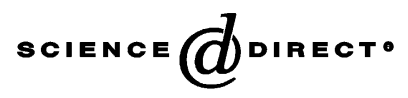

Behavioural Processes 65 (2004) 221-229

\section{BeHAVIOURAL Processes}

www.elsevier.com/locate/behavproc

\title{
Dissociation between the Espinet and perceptual learning effects in flavour aversion conditioning
}

\author{
José Prados $^{\mathrm{a}, *}$, Geoffrey Hall ${ }^{\mathrm{b}}$, Sarah Leonard ${ }^{\mathrm{b}}$ \\ a Departament de Psicologia Bàsica, Universitat de Barcelona, Passeig Vall d'Hebron 171, 08035 Barcelona, Spain \\ b Department of Psychology, University of York, Y010 5DD York, UK
}

Received 25 September 2003; received in revised form 25 September 2003; accepted 7 October 2003

\begin{abstract}
In three experiments rats were given pre-exposure to two compound flavours, $\mathrm{AX}$ and $\mathrm{BX}$, the two compounds being presented for some subjects on alternate trials (the intermixed schedule) and, for others, in separate blocks of trials (the blocked schedule). After aversion conditioning with A (in Experiments 1 and 2), the inhibitory properties of B were tested using both retardation (Experiment 1) and summation tests (Experiment 2). The results failed to support the proposal [Anim. Learn. Behav. 23 (1995) 361] that B should acquire inhibitory properties in the intermixed condition (the "Espinet effect"). Experiment 3 demonstrated that generalisation to $\mathrm{BX}$ after conditioning with $\mathrm{AX}$ was attenuated by intermixed pre-exposure (a perceptual learning effect). This pattern of results challenges the hypothesis that inhibitory learning during intermixed pre-exposure to $\mathrm{AX}$ and $\mathrm{BX}$ can account for both the Espinet and the perceptual learning effects.
\end{abstract}

(C) 2003 Elsevier B.V. All rights reserved.

Keywords: Perceptual learning; Espinet effect; Generalisation; Inhibitory learning; Flavour aversion

\section{Introduction}

Subjects that are required to learn to discriminate between two similar stimuli can sometimes benefit from pre-exposure to the stimuli. For instance, Symonds and Hall (1995, Experiment 2) gave rats pre-exposure on separate, alternating trials, to two compound flavours, AX and BX (where A and B represent sucrose and saline solutions, and $\mathrm{X}$ that a small amount of acid was added to each solution in order to render the compounds more similar). Control subjects also received exposure to the stimuli, but according to a different schedule-they received a block of AX trials followed by a separate block of BX trials (or vice

\footnotetext{
* Corresponding author. Tel.: +34-933125146; fax: +34-934021363.

E-mail address: jprados@psi.ub.es (J. Prados).
}

versa). The rats then received conditioning trials with $\mathrm{AX}$ as the conditioned stimulus (CS) and an injection of lithium chloride $(\mathrm{LiCl})$ as the unconditioned stimulus (US). A subsequent generalisation test showed that the rats given the intermixed pre-exposure schedule consumed $\mathrm{BX}$ more readily than the rats given the blocked schedule of pre-exposure (see also Bennett et al., 1999; Mondragón and Hall, 2002). This result has been taken to be an instance of perceptual learning - as evidence that alternating pre-exposure to $\mathrm{AX}$ and $\mathrm{BX}$ engages learning processes that enhance the discriminability of the stimuli. The experiments to be reported here continue investigation of the effects of these different schedules of pre-exposure with the intention of testing the validity of the account proposed by McLaren et al. (1989) (see also McLaren and Mackintosh, 2000) as an explanation for this version of the perceptual learning effect. 
McLaren et al. (1989) have pointed out that, according to the standard principles of associative learning, pre-exposure to compound stimuli will establish a range of associations among their constituent elements. In both the intermixed and blocked schedules, excitatory within-compound associations (between A and $\mathrm{X}$ and between $\mathrm{B}$ and $\mathrm{X}$ ) can be expected to form. Additionally the intermixed procedure could allow the development of inhibitory associations between the unique features ( $\mathrm{A}$ and $\mathrm{B}$ ) of the pre-exposed stimuli. In animals given this schedule, presentation of $\mathrm{AX}$ would be able to activate a representation of B (by way of the X-B link); similarly, presentation of BX would be able to activate a representation of $\mathrm{A}$ (via the $\mathrm{X}-\mathrm{A}$ link). According to standard associative theory (e.g. McLaren and Mackintosh, 2000; Rescorla and Wagner, 1972; Wagner, 1981) these are the conditions under which inhibitory links will form between A and B and between B and A. Such links will form much less readily in the blocked condition. To take the case in which the AX block precedes the BX block (similar considerations apply in animals given the reverse arrangement), there is no opportunity for inhibitory associations to be established from $\mathrm{A}$ to $\mathrm{B}$, since during the block of AX presentations B is not yet predicted by the presence of $\mathrm{X}$. And although the second block of (BX) trials might, in principle, allow the formation of an inhibitory association from B to A, such an association would only be weak given that the excitatory A-X association on which it depends would be expected to extinguish over the course of these trials.

The existence of inhibitory associations between A and $\mathrm{B}$ could influence the extent to which a conditioned response (CR) established to AX generalises to $\mathrm{BX}$. The conditioning trials with $\mathrm{AX}$ will result in the formation of associations between A and the US and between $\mathrm{X}$ and the US and will also re-establish the within-compound $\mathrm{A}-\mathrm{X}$ association for all animals. When animals in the blocked condition are tested with $\mathrm{BX}$, their response will be determined not only by the direct X-US association but also by the ability of $\mathrm{X}$ to activate the representation of A (by way of the $\mathrm{X}-\mathrm{A}$ association) and thus to contact a representation of the US by way of the chain $\mathrm{X}-\mathrm{A}-\mathrm{US}$. This latter source of responding will not be available to animals given intermixed pre-exposure for whom the presence of $\mathrm{B}$ on test will serve to inhibit activation of the repre- sentation of A. The result will be a weaker CR after intermixed than after blocked pre-exposure.

Support for this hypothesis has been sought in experiments that have attempted to demonstrate that intermixed exposure to AX and BX does indeed establish inhibitory links between A and B. One line of evidence comes from a series of experiments by Espinet et al. (1995). In these experiments, rats were given conditioning with A element alone after intermixed exposure to $\mathrm{AX}$ and $\mathrm{BX}$, and the consequences for the B element were tested. It was found that pairing A with US appeared to endow B with the properties of an inhibitor for that US (an outcome that has come to be referred to as "the Espinet effect"). When flavour B was subsequently paired with the US, it was found that the rats were slow to acquire an aversion to it (that is B "passed" the retardation test for conditioned inhibition). And if another flavour, Q, was paired with the US, the aversion conditioned to Q was alleviated by adding $\mathrm{B}$ to $\mathrm{Q}$ (the summation test for conditioned inhibition, see also Artigas et al., 2001.) Espinet et al. argued that the inhibitory properties shown by $\mathrm{B}$ on these tests was a consequence of the formation of inhibitory links between A and B during pre-exposure. They considered more than one possible mechanism, but that subsequently adopted (see McLaren and Mackintosh, 2000) proposes that the effect occurs because of the ability of B to inhibit A. When B is presented in the test phase, not only will it suppress the activation of the A representation but it will also suppress the activation of the associate of A, which in this case will be the US.

The notion that intermixed pre-exposure to $A X$ and BX will establish inhibitory links between A and B thus provides an account for both the Espinet and the perceptual learning effects. It should be noted, however, that evidence for the role of this inhibitory mechanism in the perceptual learning effect comes from comparison of a group given the intermixed pre-exposure schedule with that of groups given the blocked schedule. In the experiments by Espinet et al. (1995), however, different control groups were used, for example, comparison was made between subjects given intermixed pre-exposure to $\mathrm{AX}$ and $\mathrm{BX}$ and control subjects pre-exposed to $\mathrm{A}$ and $\mathrm{B}$ alone in the absence of the common X element. It is important, therefore, to see if the Espinet effect can be demonstrated when the comparison is with the blocked control. Experiments that make such a comparison 
(and that succeeded in finding the effect) have been reported by Leonard and Hall (1999), but these used a procedure (conditioned suppression with auditory and visual cues) quite different from that used in the experiments considered so far; what is more, our attempts to demonstrate the perceptual learning effect in the conditioned suppression procedure have so far proved unsuccessful (Leonard, 1999). In the experiments that follow, therefore, we will look for the Espinet effect comparing intermixed and blocked pre-exposure procedures in a flavour aversion preparation, using exactly the same stimuli and pre-exposure procedures as are known to be effective in producing the perceptual learning effect.

\section{Experiment 1}

The aim of this experiment was to see whether the Espinet effect could be found in animals given intermixed pre-exposure to the compound flavours AX and $\mathrm{BX}$, comparison being made with control groups given exposure to $\mathrm{AX}$ and $\mathrm{BX}$ in separate blocks of trials. After the pre-exposure phase was completed, all animals received conditioning with $\mathrm{A}$ as the CS. The final test phase consisted in the conditioning of an aversion to flavour B. If the exposure establishes inhibitory links between $\mathrm{A}$ and $\mathrm{B}$, and if such links mean that conditioning with A makes B an inhibitor for the US, then acquisition by B should be retarded. The proposal that inhibitory links will form during intermixed and not during blocked pre-exposure implies that acquisition to B should proceed less readily in the intermixed than in the blocked group.

\subsection{Method}

\subsubsection{Subjects and apparatus}

The subjects were 24 male naive hooded Lister rats, with a free-feeding body weight of $398 \mathrm{~g}$ (range: $355-450 \mathrm{~g}$ ) at the start of the experiment. They were housed in individual cages with continuous access to food in a colony room that was artificially lit from 08:00 to 20:00 h each day. They were given continuous access to food, but access to water was restricted as detailed in the following.

The solutions used as experimental stimuli were administered, in the home cages, at room tempera- ture, in a 50-ml plastic centrifuge tube fitted with a rubber stopper and a stainless steel drinking spout. The following flavoured solutions were used: a compound consisting of $0.01 \mathrm{M}$ hydrochloric acid $(\mathrm{HCl})$ and $0.16 \mathrm{M}$ saline $(\mathrm{NaCl})$; a compound of $0.01 \mathrm{M} \mathrm{HCl}$ and $0.33 \mathrm{M}$ sucrose; a $0.16 \mathrm{M}$ solution of $\mathrm{NaCl}$; and a $0.33 \mathrm{M}$ sucrose solution. Consumption was measured, by weighing, to the nearest $0.1 \mathrm{ml}$.

\subsubsection{Procedure}

The experiment started with a water deprivation schedule. The standard water bottles were first removed overnight. On the following three days, access to water was restricted to two daily sessions of $30 \mathrm{~min}$ initiated at 11:00 and 16:00 h. Presentations of fluids continued to be given at these times throughout the experiment. On the last day of this cycle, water intakes were measured, and subjects were assigned to three equal-sized groups matched in their levels of water consumption.

Over the next 12 days (the pre-exposure phase), all rats received six 8-ml presentations of each compound flavour, always presented for $30 \mathrm{~min}$ at 11:00 h. Rats in group I (intermixed) were given pre-exposure to $\mathrm{AX}$ and BX on alternate days; rats in the B (blocked) groups were given blocks of six trials with $\mathrm{AX}$ and six trials with BX. Group B1 was given pre-exposure to AX on days 1-6 and to BX on days 7-12; group $\mathrm{B} 2$ was given pre-exposure to $\mathrm{BX}$ on the first six days and to AX on the last six days. For half the animals in each group flavour A was saline and flavour B was sucrose; for the remainder the arrangement was reversed. For all rats, flavour $\mathrm{X}$ was $\mathrm{HCl}$. Throughout the experiment, all the subjects were allowed $30 \mathrm{~min}$ of free access to water from the standard bottles at 16:00 h.

On the day after the end of pre-exposure the first conditioning trial was given in which all the subjects were presented with $8 \mathrm{ml}$ of A followed by an injection of $0.3 \mathrm{M} \mathrm{LiCl}$ at $10 \mathrm{ml} / \mathrm{kg}$ of body weight. After the recovery day, in which all the animals had access to water in their home cages at 11:00 and 16:00 h, a further conditioning trial was given in which the subjects were given free access to A for $30 \mathrm{~min}$ before being injected with $\mathrm{LiCl}$. After a further recovery day, a non-reinforced test trial was given in which all the subjects had free access to A for $30 \mathrm{~min}$.

On the next day the retardation phase of the experiment began and all the rats were presented with $8 \mathrm{ml}$ of 
B followed by an injection of $0.15 \mathrm{M} \mathrm{LiCl}$ at $3 \mathrm{ml} / \mathrm{kg}$. The magnitude of the US was reduced from that used for conditioning with $\mathrm{A}$ in an attempt to ensure that acquisition of the aversion to B would occur relatively slowly, allowing differences between the groups to be observed. After a recovery day, the rats were given free access to B before receiving an injection of lithium. This two-day cycle was then repeated twice.

\subsection{Results and discussion}

There was some evidence of neophobia on the early trials, but thereafter the rats reliably consumed all the fluid offered on each trial of pre-exposure. The conditioning procedure successfully established an aversion to A. On the first trial all animals consumed the full amount offered, but consumption was substantially reduced after the second conditioning trial. The group mean consumption scores on the second conditioning and test trials for subjects in group I were 10.70 and $1.17 \mathrm{ml}$, respectively; the equivalent scores for the subjects in group B1 were 8.09 and $1.39 \mathrm{ml}$; those for the subjects in group B2 were 9.07 and $0.64 \mathrm{ml}$. An analysis of variance (ANOVA) conducted on these scores, with group and trial as the variables, revealed a significant effect of trial, $F(1,21)=71.01$, but there was no significant effect of group or of the interaction between the variables $(F \mathrm{~s}<1)$. In this and in subsequent statistical analyses a significance level of $P<0.05$ was adopted.

On the first conditioning trial with $\mathrm{B}$, all animals consumed the full amount offered. Fig. 1 shows group means for consumption of $\mathrm{B}$ across the final three trials of the retardation test. It is evident that an aversion was acquired in all three groups and that on all three trials the group I consumed slightly more than group B1, which in turn consumed slightly more than group B2. These differences among the groups were, however, rather small and proved not to be statistically reliable. An ANOVA conducted on the data summarised in the figure, with group and trial as the variables yielded only a significant effect of trial, $F(2,42)=98.27$. Neither the main effect of group, $F(2,21)=2.87$, nor the Group $\times$ Trial interaction $(F<1)$ was significant.

Although the animals in group I showed consistently higher levels of consumption on the test than did animals in the blocked groups, the present results provide no statistically reliable support for the pro-

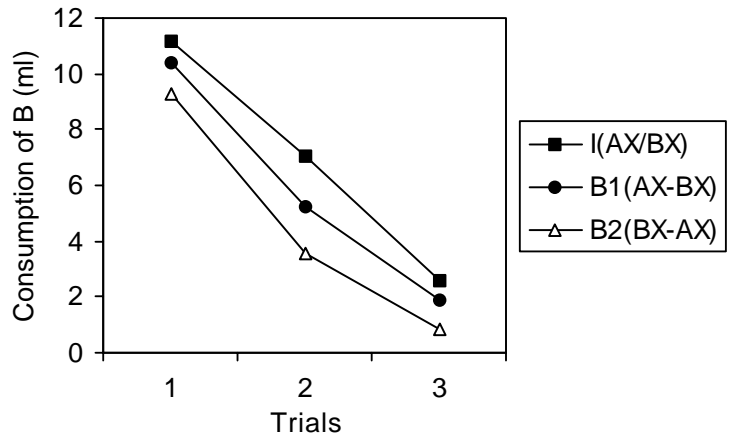

Fig. 1. Mean intake of flavour B in the retardation test of Experiment 1 . All animals had previously received conditioning with A as the CS. Group I had received pre-exposure to $\mathrm{AX}$ and $\mathrm{BX}$ on alternating trials; the $\mathrm{B} 1$ and $\mathrm{B} 2$ groups had received pre-exposure to $\mathrm{AX}$ and $\mathrm{BX}$ on separate blocks of trials.

posal that conditioning with A makes B an inhibitor for the US after intermixed but not after blocked pre-exposure. It should be acknowledged, however, that the retardation test used here may not be the best way of assessing such inhibition. In a recent experiment, Mondragón and Hall (2002) examined the rate at which conditioning occurred to one of the unique stimulus elements (i.e. to A or B) after the two forms of pre-exposure. They found that learning occurred more readily after intermixed than after blocked pre-exposure, and they suggested, in explanation, that the salience or associability of the unique elements is maintained during intermixed, but declines during blocked pre-exposure. Whatever the merits of this explanation, it raises the possibility that the test procedure used in the present experiment underestimated the inhibitory strength of B in group I-that the retardation of conditioning produced by the existence of inhibition between B and the US might have been obscured by an enhancement of the associability of this stimulus, a factor that would tend to facilitate learning. The next experiment therefore looked for evidence of B's inhibitory properties using a test (the summation test) that does not require the formation of a new association by $\mathrm{B}$.

\section{Experiments $2 \mathrm{~A}$ and 2B}

In this experiment rats were given intermixed or blocked pre-esposure to $\mathrm{AX}$ and $\mathrm{BX}$ followed by 
conditioning with A as the CS, as in Experiment 1. An aversion was then established to a novel flavour, quinine $(\mathrm{Q})$, and all the animals were tested with the compound BQ. Differences between the groups in the associability of B should be without influence on this test, but if $\mathrm{B}$ has acquired inhibitory properties in group I the consumption of the BQ compound should be greater in this group than in those that received blocked pre-exposure.

\subsection{Experiment $2 A$}

\subsubsection{Method}

The subjects were 30 male naive hooded Lister rats with a mean free-feeding weight of $466 \mathrm{~g}$ (range $430-540 \mathrm{~g}$ ). They were maintained in the same way and on the same water deprivation schedule as was used in Experiment 1. They were randomly assigned to one of the three equal-sized groups, the pre-exposure conditions: I, B1, and B2. In addition to the flavours employed in Experiment 1 we also made use of a $0.00005 \mathrm{M}$ quinine sulphate solution $(\mathrm{Q})$ and of the two compounds, quinine-salt and quinine-sucrose (the BQ compounds), during the summation test.

The two first phases of the experiment (pre-exposure and conditioning with flavour A) proceeded exactly as described for Experiment 1. The next phase consisted of the conditioning of an aversion to Q. All the rats were given access to $8 \mathrm{ml}$ of $\mathrm{Q}$ and then injected with $0.3 \mathrm{M}$ solution of $\mathrm{LiCl}$ at $10 \mathrm{ml} / \mathrm{kg}$ of body weight. After a recovery day, there was a test trial in which the rats were given free access to $\mathrm{Q}$ for $30 \mathrm{~min}$. The last three days of the experiment constituted the summation test phase; on these all the subjects were given free access to the $\mathrm{BQ}$ compound for $30 \mathrm{~min}$ in the morning drinking sessions. In respects not specified here the procedure was the same as that described for Experiment 1.

\subsubsection{Results and discussion}

As in Experiment 1, there was some evidence of neophobia on the early trials, but thereafter the rats reliably consumed all the fluid offered on each trial of pre-exposure. The conditioning procedure successfully established an aversion to A. On the first trial all animals consumed the full amount offered, but consumption was substantially reduced after the second conditioning trial. The group mean scores on the sec- ond conditioning trial and the test trial for subjects in group I were 8.32 and $1.85 \mathrm{ml}$, respectively; those for the subjects in group B1 were 7.81 and $0.36 \mathrm{ml}$; those for the subjects in group B2 were 7.15 and 0.39. An ANOVA with group and trials as factors showed a significant effect of the factor trial, $F(1,27)=69.78$. The effect of group and the interaction between the variables were not significant $(F \mathrm{~s}<1)$.

Although most rats did not consume the full amount made available on the conditioning trial with $\mathrm{Q}$, the groups did not differ in this respect. Group I consumed a mean of $4.80 \mathrm{ml}$, group B1 of $4.86 \mathrm{ml}$, and group B2 of $4.03 \mathrm{ml}$. An ANOVA conducted on these data confirmed that there were no significant differences among groups $(F<1)$. The conditioning procedure successfully established an aversion to Q; on the test trial that followed conditioning (the results of which are shown on the left of the left panel of Fig. 2) all three groups showed an almost total rejection of the quinine solution.

The left panel of Fig. 2 also shows the results of the three trials of the summation test in which BQ was presented. All three groups drank somewhat more of BQ than of Q, an outcome that might be taken to imply that B was inhibitory in all three but which is also to be expected on the basis of the principle of generalisation decrement. There was no indication that $\mathrm{B}$ was more effective in alleviating the suppression of consumption in group I than in the B groups. An ANOVA conducted on the data for BQ consumption, with group and trial as the variables, revealed a significant effect of trial, $F(2,54)=17.52$, but the effect of group and the Group $\times$ Trial interaction were not significant $(F \mathrm{~s}<1)$.

The present results seem to confirm those of Experiment 1 ; in neither experiment was there evidence of that $\mathrm{B}$ acquired inhibitory properties in group I but not in the B groups. It should be acknowledged, however, that the (non-significant) difference observed in the numerical scores was again in the direction predicted by the hypothesis under test (group I drank marginally more of BQ than either of the other two groups). Given that the aversion to $\mathrm{Q}$ was very profound and that no group drank much of $\mathrm{BQ}$, it is possible that our failure to find a difference among the groups was simply the consequence of a "floor" effect. A further experiment was conducted in order to address this issue. 

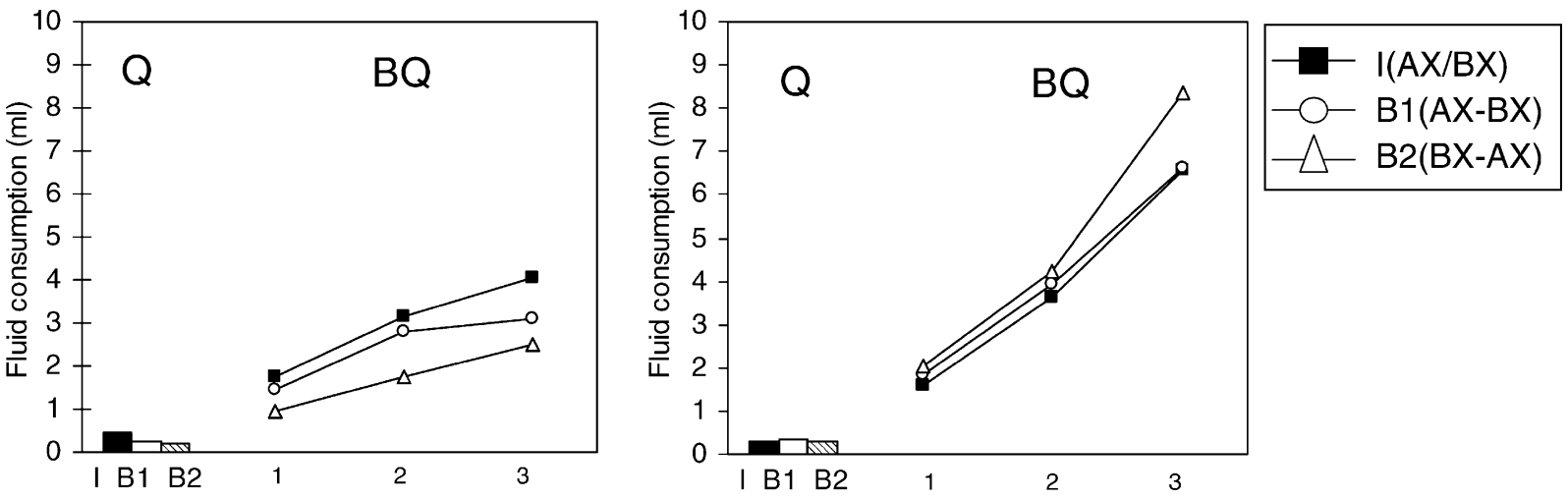

Fig. 2. Mean intake of flavour Q alone and the compound solution BQ in the summation tests of Experiment $2 \mathrm{~A}$ (left panel) and Experiment 2B (right panel). All animals had previously received conditioning with A as the CS. Group I had received pre-exposure to AX and BX on alternating trials; the $\mathrm{B} 1$ and $\mathrm{B} 2$ groups had received pre-exposure to $\mathrm{AX}$ and $\mathrm{BX}$ on separate blocks of trials.

\subsection{Experiment $2 B$}

In this experiment, we conducted a replication of Experiment 2A, but with procedural modifications intended to increase the sensitivity of the summation test. Most importantly, we reduced the US magnitude used in the conditioning with Q so that higher levels of fluid consumption might be obtained during the summation test. In addition we eliminated the non-reinforced test of A that was given after conditioning with $\mathrm{A}$ in the previous experiment. Since the hypothesis under test requires that $\mathrm{A}$ has associative strength at the time B is tested, we wanted to avoid the possibility that A might have extinguished during this test.

\subsubsection{Method}

The subjects were a further 24 male naive hooded Lister rats with a mean free-feeding weight of $390 \mathrm{~g}$ (range 350-430 g). The procedure for this experiment was identical to that described for Experiment 2A except that the conditioning trial with $\mathrm{Q}$ was given on the day following the completion of phase of conditioning with $\mathrm{A}$, and the US for conditioning with Q was an injection of $0.15 \mathrm{M} \mathrm{LiCl}$ at $10 \mathrm{ml} / \mathrm{kg}$ of body weight. A non-reinforced test trial with $\mathrm{A}$ was given on the day following the last summation test.

\subsubsection{Results and discussion}

There was some evidence of neophobia on the early trials, but thereafter the rats reliably consumed all the fluid offered on each trial of pre-exposure. On the first conditioning trial in which A was presented, all animals consumed the full amount offered. The group mean score on the second conditioning trial for subjects in group I was $9.05 \mathrm{ml}$; that for the subjects in group B1 was 7.97 and for the subjects in group B2 was $11.38 \mathrm{ml}$. That this second conditioning trial was effective in establishing an aversion to A was shown by the results of the final test trial with A. All animals showed a reduced level of consumption on this trial, the mean scores being $0.64 \mathrm{ml}$ for group I, $0.47 \mathrm{ml}$ for group B1, and $1.35 \mathrm{ml}$ for group B2. An ANOVA conducted on the test-trial data confirmed that there were no significant differences among the groups $(F<1)$.

On the conditioning trial with $\mathrm{Q}$, group I consumed a mean of $3.28 \mathrm{ml}$, group B1 of $2.96 \mathrm{ml}$, and group B2 of $4.01 \mathrm{ml}$. An ANOVA conducted on these data confirmed that there were no significant differences among groups $(F<1)$. Although, as in Experiment $2 \mathrm{~A}$, this trial produced a profound aversion in all animals (as the right-hand panel of Fig. 2 shows, negligible amounts of quinine were consumed on the test trial that followed conditioning), levels of consumption were higher in this experiment during the summation test with BQ. None the less, as Fig. 2 also shows, there were no substantial differences among the groups. An ANOVA conducted on the summation test data, with group and trial as the variables, revealed only a significant effect of trial, $F(2,42)=42.72$; neither the effect of group nor the Group $\times$ Trial interaction were significant $(F \mathrm{~s}<1)$. This outcome matches 
that of Experiment 2A in failing to detect any evidence that B had acquired inhibitory properties in group I.

\section{Experiment 3}

Experiments 1 and 2 have failed to find any evidence of the Espinet effect-neither retardation nor summation tests revealed any difference between the intermixed and blocked pre-exposure conditions in the effectiveness of B as an inhibitor for the US. Given that the comparison between intermixed and blocked pre-exposure reliably produces a perceptual learning effect, our new results cast doubt on the proposal that a common mechanism (the development of inhibitory links between A and B) is responsible for both phenomena. It should be acknowledged, however, that the pre-exposure procedure used in these experiments was slightly different from that usually used in demonstrating the perceptual learning effect. Thus, for example, Symonds and Hall (1995) gave pre-exposure to AX and BX in two daily sessions over the course of four consecutive days whereas in Experiments 1 and 2 we gave pre-exposure to these flavours once a day over the course of 12 days. In order to establish a dissociation between the Espinet and perceptual learning effects, it is necessary to demonstrate that the latter can be obtained with the pre-exposure procedure used in Experiments 1 and 2. This was the aim of the present experiment.

\subsection{Method}

The subjects were 16 male naive hooded Lister rats with a mean free-feeding weight of $403 \mathrm{~g}$ (range $360-425 \mathrm{~g}$ ). They were maintained in the same way and on the same water deprivation schedule as was used in Experiments 1 and 2. They were randomly assigned to one of two pre-exposure conditions, I and B1 (we omitted the B2 condition as, neither in the experiments described above, nor in others reported previously, e.g. Symonds and Hall, 1995, have we been able to detect any marked difference between the two versions of the blocked schedule). The compound flavours (AX and BX) employed in the previous experiments were used. The unconditioned stimulus for the conditioning trials was a $10 \mathrm{ml} / \mathrm{kg}$ injection of $0.3 \mathrm{M} \mathrm{LiCl}$.

The pre-exposure phase was conducted exactly as described for Experiments 1 and 2. There followed three conditioning trials on each of which the rats were given access to $10 \mathrm{ml}$ of $\mathrm{AX}$ before being injected with $\mathrm{LiCl}$. The day after the final post-conditioning recovery day, all subjects were given free access to $\mathrm{BX}$ in the morning drinking session for $30 \mathrm{~min}$.

\subsection{Results and discussion}

Conditioning with AX successfully established an aversion to this compound in both groups. Fig. 3 (on the left) shows group means for consumption of AX across the three conditioning trials. An ANOVA conducted on these data, with group and trial as
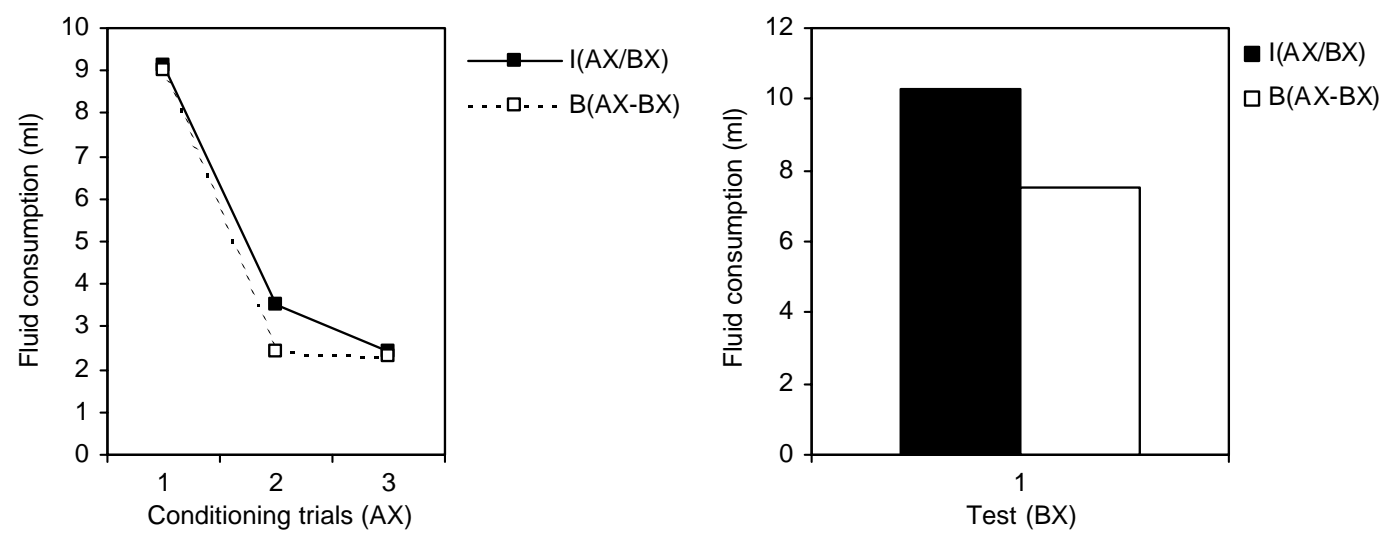

Fig. 3. Mean intake of flavour AX in the conditioning phase (left panel) and of flavour BX in the test trial (right panel) of Experiment 3. Group I had received pre-exposure to $\mathrm{AX}$ and $\mathrm{BX}$ on alternating trials; group $\mathrm{B} 1$ had received pre-exposure to $\mathrm{AX}$ and $\mathrm{BX}$ on separate blocks of trials. 
the variables, revealed a significant effect of trial, $F(2,28)=134.16$, but no effect of group or of the interaction between the variables $(F \mathrm{~s}<1)$.

The groups differed in their performance on the test trial (Fig. 3, on the right). These scores differed reliably, $F(1,14)=7.75$. This outcome confirms that the perceptual learning effect (less generalisation from AX to BX after intermixed than after blocked pre-exposure) can be obtained with the pre-exposure regime used in the present series of experiments.

\section{General discussion}

It has been proposed (Espinet et al., 1995; McLaren and Mackintosh, 2000) that a common mechanism underlies the Espinet and the perceptual learning effects. In both procedures, animals in the critical experimental condition are given pre-exposure to intermixed presentations of the compounds $\mathrm{AX}$ and $\mathrm{BX}$, an arrangement that might be expected, according to standard associative principles, to establish inhibitory links between the unique features A and B. These links, it has been argued, are responsible both for the inhibitory properties that $\mathrm{B}$ has been found to acquire after excitatory conditioning with A (the Espinet effect), and also for the fact that generalisation from $\mathrm{AX}$ to $\mathrm{BX}$ is restricted by intermixed pre-exposure (the perceptual learning effect). The experiments reported here, by establishing a dissociation between the two effects, call this analysis into question. When comparison was made with a control group given pre-exposure to AX and BX on separate blocks of trials (a schedule that would not be expected to establish inhibitory links between $\mathrm{A}$ and $\mathrm{B}$ ), the perceptual learning effect was still found (Experiment 3). But neither retardation (Experiment 1) nor summation (Experiment 2) tests produced evidence for a difference between the groups in the inhibition acquired by B after conditioning with A.

Given this pattern of results, some additional assumptions will be required to maintain the position that the Espinet and perceptual learning effects are both the product of a common mechanism. One possibility is to accept the results of Experiments 1 and 2 as demonstrating that, for the procedures used here, the intermixed schedule is little more effective than the blocked schedule at generating inhibition between A and B. Although we may accept that standard associa- tive theory predicts the formation of inhibitory links only in the intermixed case it does not follow that the links established by our procedure will be powerful enough to produce a marked effect in the test phase. In particular, McLaren and Mackintosh (2000) have argued that the formation of inhibitory associations between $\mathrm{A}$ and $\mathrm{B}$ depends on prolonged exposure to $\mathrm{AX}$ and BX, a notion supported by the results of Espinet et al. (1995, Experiment 4) who found evidence for inhibition between A and B in rats given 12 days of exposure to each but not in rats given 4 days of exposure to each. It is possible that our Experiments 1 and 2 would have succeeded in revealing a difference between the intermixed and blocked conditions had more pre-exposure been given. What remains the case, however, is that the pre-exposure regime used in the present experiments was sufficient to produce the perceptual learning effect in Experiment 3. If both the perceptual learning effect and the Espinet effect depend on the formation of mutually inhibitory links between A and $B$, then it needs to be explained why one effect should appear after relatively few exposure trials whereas the other can be found only after prolonged exposure.

A second possibility is that our intermixed preexposure procedure was fully effective in establishing inhibitory links between A and B (and that the perceptual learning effect is indeed dependent on the formation of such links), but that the procedure used to assess these in Experiments 1 and 2 was, in some way, less sensitive than that used in Experiment 3. It might be argued, for instance, that only in Experiment 3 was a strong associate of $\mathrm{A}$ (namely $\mathrm{X}$ ) present at the time of test. This factor may have made the test procedure more sensitive to the ability of B to inhibit A. It still remains true, however, that, unlike Espinet et al. (1995), we were unable to find evidence of the acquisition of inhibition by $\mathrm{B}$ after intermixed pre-exposure to AX and BX. Our experiments differed from theirs chiefly in the nature of the control group that was used-we used the blocked condition whereas they (in the study most closely comparable to ours) gave the control subjects pre-exposure to A and B in the absence of the common element, X. According to standard associative theory, inhibition between A and B should be generated in neither of these control conditions. A possible conclusion, therefore, is that the Espinet effect is not a consequence of the fact that the intermixed condition generates inhibition between $\mathrm{A}$ 
and $\mathrm{B}$ but depends rather on some other process that operates only in the particular conditions investigated by Espinet et al.

In view of these complications, it is appropriate to consider the further possibility that different mechanisms underlie the Espinet and perceptual learning effects. We may allow that intermixed exposure to AX and BX can, in some circumstances, establish inhibition between A and B (this follows from the standard assumptions of associative learning theory and has received experimental support from experiments by Dwyer et al., 2001, and by Dwyer and Mackintosh, 2002). But, as the present experiments show, the circumstances that produce the perceptual learning effect do not necessarily produce the Espinet effect. Perhaps then the perceptual learning effect obtained in the present Experiment 3 is the consequence of some quite different mechanism; Hall (2003; see also Mondragón and Hall, 2002) has outlined one possibility.

\section{Acknowledgements}

This research was supported by grants from the UK Biotechnology and Biological Sciences Research Council and the Spanish Ministerio de Ciencia y Tecnología (BSO2001-3503).

\section{References}

Artigas, A.A., Chamizo, V.D., Peris, J.M., 2001. Inhibitory associations between neutral stimuli: a comparative approach. Anim. Learn. Behav. 29, 46-65.

Bennett, C.H., Scahill, V.L., Griffiths, D.P., Mackintosh, N.J., 1999. The role of inhibitory associations in perceptual learning. Anim. Learn. Behav. 27, 333-345.
Dwyer, D.M., Mackintosh, N.J., 2002. Alternating exposure to two compound flavors creates inhibitory associations between their unique features. Anim. Learn. Behav. 30, 177-200.

Dwyer, D.M., Bennett, C.H., Mackintosh, N.J., 2001. Evidence for inhibitory associations between the unique elements of two compound flavours. Quarterly J. Exp. Psychol. 54B, 97-107.

Espinet, A., Iraola, J.A., Bennett, C.H., Mackintosh, N.J., 1995. Inhibitory associations between neutral stimuli in flavor-aversion conditioning. Anim. Learn. Behav. 23, 361-368.

Hall, G., 2003. Learned changes in the sensitivity of stimulus representations: associative and nonassociative mechanisms. Quarterly J. Exp. Psychol. 56B, 43-55.

Leonard, S., 1999. Mediated Learning in the Rats: Implications for Perceptual Learning. Unpublished Doctoral Dissertation, University of York.

Leonard, S., Hall, G., 1999. Representation-mediated inhibitory learning in the conditioned-suppression procedure. Quarterly J. Exp. Psychol. 52B, 145-158.

McLaren, I.P.L., Mackintosh, N.J., 2000. An elemental model of associative learning: I. Latent inhibition and perceptual learning. Anim. Learn. Behav. 28, 211-246.

McLaren, I.P.L., Kaye, H., Mackintosh, N.J., 1989. An associative theory of the representation of stimuli: applications to perceptual learning and latent inhibition. In: Morris, R.G.M. (Ed.), Parallel Distributed Processing: Implications for Psychology and Neurobiology. Oxford Clarendon Press, pp. 102130 .

Mondragón, E., Hall, G., 2002. Analysis of the perceptual learning effect in flavour aversion learning: evidence for stimulus differentiation. Quarterly J. Exp. Psychol. 55B, 153-169.

Rescorla, R.A., Wagner, A.R.,1972. A theory of Pavlovian conditioning: variations in the effectiveness of reinforcement and nonreinforcement. In Black, A.H., Prokasy, W.F. (Eds.), Classical Conditioning II: Current Research and Theory. Appleton-Century-Crofts, New York, pp. 64-99.

Symonds, M., Hall, G., 1995. Perceptual learning in flavor aversion conditioning: roles of stimulus comparison and latent inhibition of common stimulus elements. Learn. Motiv. 26, 203-219.

Wagner, A.R.,1981. SOP: a model of automatic memory processing in animal behavior. In: Spear, N.E., Miller, R.R. (Eds.), Information Processing in Animals: Memory Mechanisms. Lawrence Erlbaum Associates, Inc., Hillsdale, NJ, pp. 5-47. 